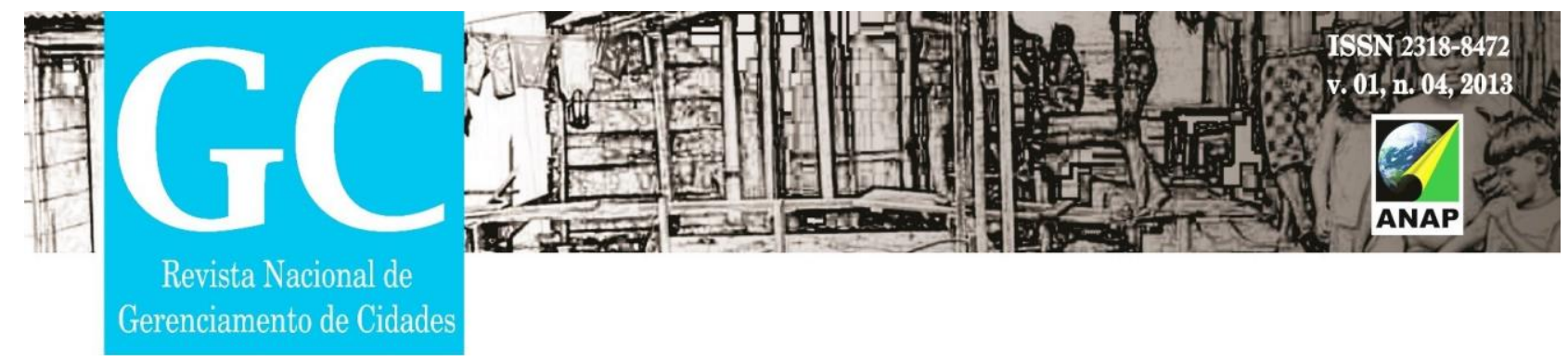

Titulo do Trabalho

\title{
A EVOLUÇÃO URBANA DE UMA CIDADE NO MEIO DO MUNDO
}

Nome do Autor (a) Principal

Ana Paula Cunha Tavares

Nome do Orientador

José Alberto Tostes

Instituição ou Empresa

Universidade Federal do Amapá - UNIFAP

E-mail de contato

anapaulactvrs@gmail.com

Palavras-chave

Planejamento Urbano, Macapá, Meio do Mundo.

\section{INTRODUÇÃO}

Macapá é a capital do estado do Amapá, localizada ao Norte do Brasil. É uma cidade média Amazônica, situada na faixa litorânea do Estado com sua costa banhada pelo Rio Amazonas. Tem como fator diferencial sua localização privilegiada, sendo a única capital brasileira "cortada" pela linha do equador. Sua conotação de cidade no meio do mundo é metafórica, entretanto essa nomenclatura lhe atribui um caráter simbólico e significativo para o estado e para o país.

É uma cidade relativamente nova, com um crescimento populacional elevado em um curto espaço de tempo, sobretudo nas últimas três décadas. Sendo assim, seu processo de evolução urbana foi conturbado, desordenado e realizado de maneira emergencial de acordo com as demandas que surgiam. Ao longo desse crescimento algumas estratégias de ordenamento urbano emergiram, através de planos diretores que 


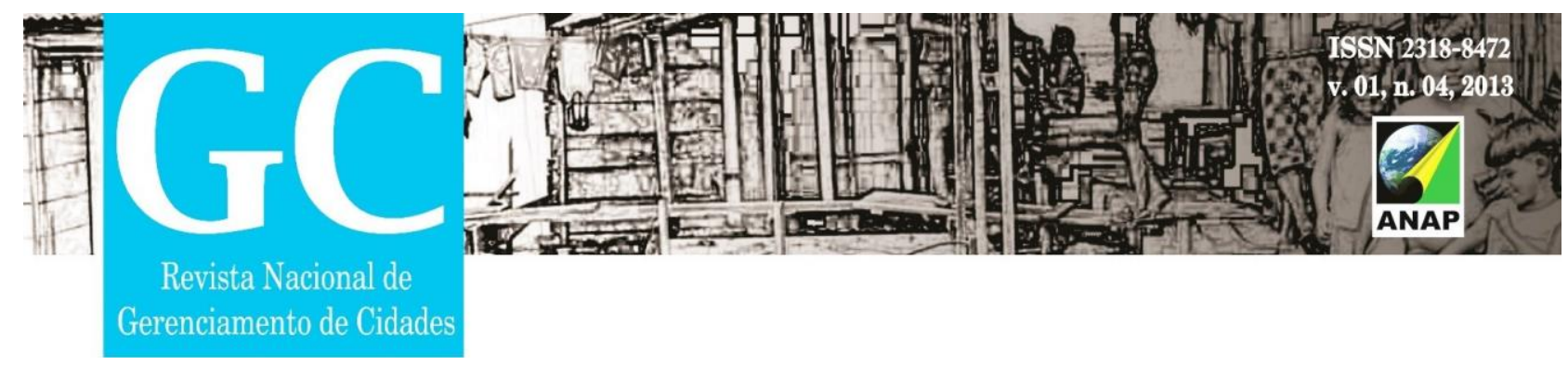

foram concebidos sob a influência de importantes acontecimentos relativos a região, como a criação do território federal do Amapá (1943) e a criação do estado do Amapá.

Tais documentos visavam melhorar a qualidade de vida da população através de políticas voltada para a infraestrutura urbana, habitação, educação, saúde e lazer, onde eram previstos projetos de expansão, desenvolvimento e melhoria do espaço urbano, atendendo à perspectivas atuais e futuras em relação ao seus anos de elaboração. No total são cinco os planos relativos à cidade de Macapá: Plano Grumbilf (1960); Plano de Desenvolvimento Urbano da Fundação João Pinheiro (1973); HJ Cole (1977); Plano Diretor de Macapá de 1990 (não oficial); Plano Diretor De Desenvolvimento Urbano E Ambiental De Macapá (2004).

Diante deste cenário, se fez necessário este estudo para analisar o processo de urbanização de Macapá através dos planos diretores, onde se percebe como ocorreu o desenvolvimento urbano da cidade, principais problemáticas e propostas de cada período. Constatam-se os fatores responsáveis pelo o que aconteceu com a cidade e as contribuições relevantes deixadas por cada plano, que influenciam a conformação espacial de uma cidade no meio do mundo.

\section{OBJETIVO GERAL}

- Compreender o planejamento e infraestrutura de uma cidade no meio do mundo, através dos seus planos urbanísticos, para que se possa entender a dinâmica que permeia o desenvolvimento urbano de uma cidade cheia de peculiaridades e simbogias. Macapá é cortada pela linha do Equador e banhada pelo rio Amazonas, característica única na região. 


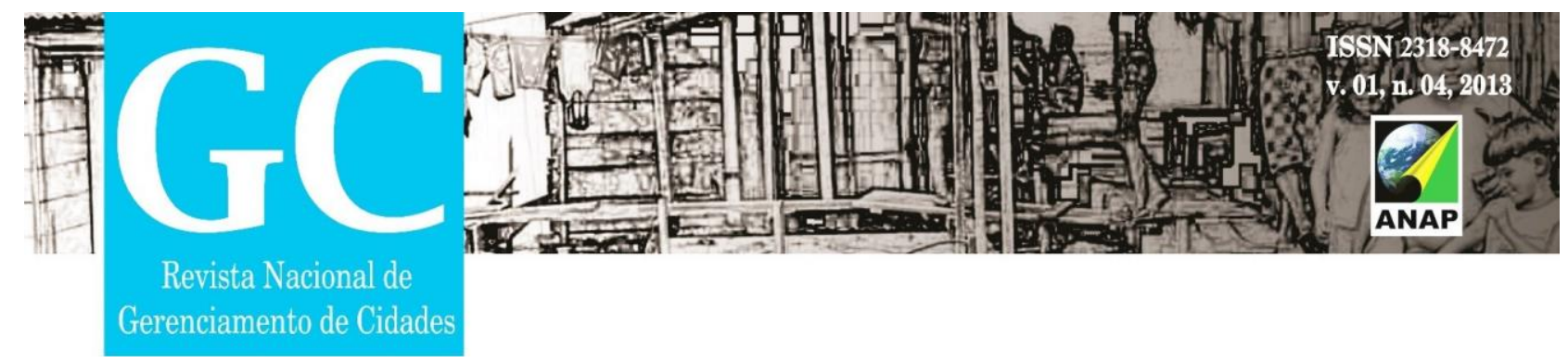

OBJETIVO ESPECÍFICO

- Identificar como os planos diretores urbanos influenciaramna configuração do desenvolvimento da cidade amazônica, sobretudo concebendo a vinculação representativa do meio do mundo e estabelecendo um comparativo do desenvolvimento urbano obtido ao longo das décadas.

\section{METODOLOGIA}

Os estudos metodológicos estão pautados na análise dos planos diretores idealizados entre 1959 a 2010. Análise do Plano Diretor da Grumbilf do Brasil de 1959, da Fundação João Pinheiro de 1973, da H. J. Cole + Associados de 1976 a 1979 e do Plano Diretor de Macapá de 1990 e 2004.

\section{RESULTADOS}

A análise dos planos diretores elaborados no período de 1959 a 2010 permite uma visão clara das condições de planejamento urbano da cidade e de sua aplicabilidade, permitindoo acompanhamento da evolução urbana da cidade, através da interpretação das cartografias idealizadas por cada plano, formando uma linha do tempo da configuração urbanística de Macapá.

Percebe-se ainda que o fato de Macapá estar localizada no meio do mundo não tem servido como usufruto para o desenvolvimento social e cultural da cidade. 


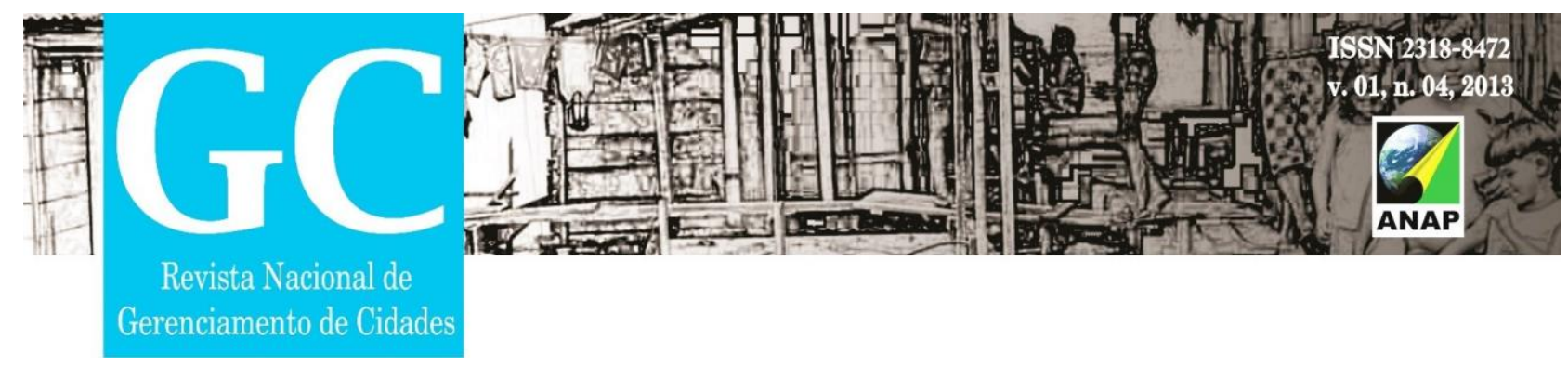

Infelizmente, o fato de localizar-se na linha do equador não tem sido um aspecto valorizado, sendo assim a população perde a identificação com tal atributo e distancia-se dele como referencial cultural próprio da região.

A dimensão simbólica do meio do mundo apresenta-se apartada do contexto da cidade. O monumento do Marco Zero, que deveria efetuar esta ligação, demonstra-se desconexo, não considerando princípios arquitetônicos, culturais, simbólicos e urbanísticos, importantes para o estabelecimento desta relação.

Os planos diretores desenvolvidos, apesar de sua qualidade técnica, pouco vislumbraram esta questão. Mesmo os planos mais palpáveis e realistas, como o Plano Diretor de 1990 e o Plano Diretor de Desenvolvimento Urbano e Ambiental do Município de Macapá de 2004, não comtemplam este ponto crucial, apresentando-se como documentos técnicos importantes mais ainda sim deficientes quanto à abrangência de todas as questões específicas do município.

\section{CONSIDERAÇÕES FINAIS}

A cidade no meio do mundo apresenta peculiaridades especificas em sua paisagem, denota-se, entretanto, ao longo de décadas, que pouco se oportunizou que esta referência se transformasse de fato em um símbolo marcante deste lugar. Apesar de rica em atrativos, Macapá apresenta-se pouco valorizada no contexto nacional, sendo conhecida apenas como capital do estado do Amapá, fragilizada quanto a presença de estrutura urbana eficiente e de qualidade.

De acordo com o IBGE (2010) a população atual da cidade é equivalente a 397.913 habitantes, sendo assim, o crescimento urbano tem causado entraves alarmantes para a população e para o município. Contudo, desde 1960 planos diretores voltados a 


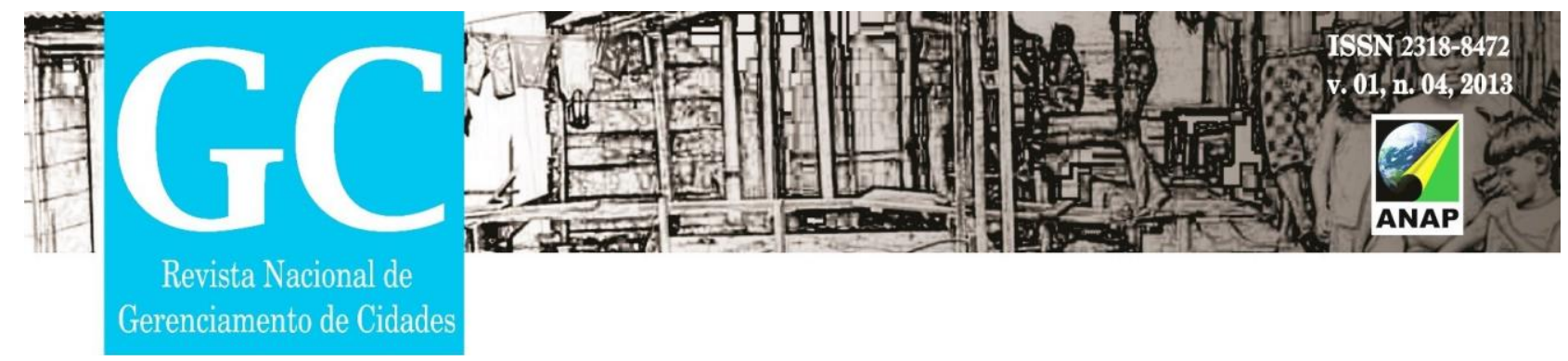

Macapá vem sendo desenvolvidos visando seu ordenamento urbano perante o crescimento populacional, buscando melhorias à conformação e estruturação da malha urbana e desenvolvimento de políticas voltadas para a qualidade de vida da população.

Segundo Tostes (2011) ocorreram várias tentativas de planejamento urbano no decorrer das décadas. O Amapá experimentou planos diretores que foram solicitados por distintos governos do Território Federal do Amapá. Os Planos Grumbilf (1960), Plano de Desenvolvimento Urbano da Fundação João Pinheiro (1973) e HJ Cole (1977), foram bons exemplos desta iniciativa. Os planos tinham ampla visão sobre o desenvolvimento urbano de áreas estratégicas para Macapá, o que não foi delineado como algo prioritário.

Após esse período surgiram mais dois planos, o Plano Diretor de 1990, que faz importantes colocações quanto a cidade, sendo o primeiro plano a contar com uma equipe de elaboração local, mas que infelizmente não foi efetivado e é considerado não oficial; e o Plano Diretor de Desenvolvimento Urbano e Ambiental de Macapá, do ano de 2004, que apresenta propostas mais atualizadas e voltadas para as questões ambientais do município, estando em constante modificação até os dias de hoje.

Lamentavelmente, os planos diretores pouco foram utilizados por gestores do Território Federal do Amapá e posteriormente por governos estaduais. Além disso, apesar de sua qualidade técnica, ainda apresentam deficiências, pouco vislumbrando Macapá como uma cidade no meio do mundo. A dimensão simbólica do meio do mundo é esquecida durante a realização do planejamento urbano, fazendo com que o processo de conformação do município não considere as peculiaridades agregadas a tal característica, tão influente como referencial cultural próprio da região.

A cada plano diretor desenvolvido surge um alento para se pensar de forma positiva a construção de uma nova agenda para Macapá, entretanto a falta de controle e a ausência de integração de políticas urbanas regionais tornaram a cidade um núcleo urbano extremamente frágil, carente de ações concretas que realizem melhorias e desenvolvam a cidade e sua conotação de "meio do mundo". 


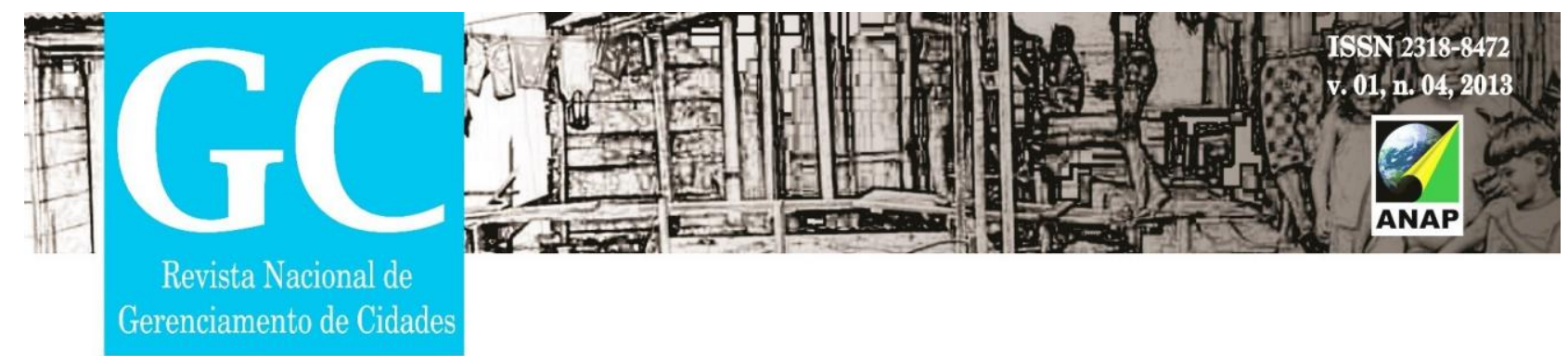

\section{REFERENCIAS}

BOTELHO, Lina Pereira. Evolução urbana da cidade de Macapá: Análise do perímetro da Fortaleza de São José de Macapá ao Araxá no período de 1950-2010.2011, Tese de Conclusão de Curso (Bacharelado em Arquitetura e Urbanismo) - UNIFAP, Santana.

AMAPÁ. Governo do Território Federal do Amapá. Planejamento Urbano, Turismo e Arquitetura. Consultoria de H. J. Cole + Associados S.A. 1976/1979.

REIS, Arthur César Ferreira. Limites e demarcações na Amazônia brasileira. Belém: SECULT, 1993.

RICCI, Magda. Contando a história do Pará: da conquista à sociedade da borracha. Belém: E-motion, 2002.

TOSTES, José Alberto. Planos diretores do estado do Amapá: uma contribuição para o desenvolvimento regional. Série Arquitetura e Urbanismo na Amazônia. Macapá-AP, Tostes, 2006.

A Dimensão simbólica do Meio do Mundo. Versão editada em http://josealbertostes.blogspot.com, acesso em 20/07/2013. 